\title{
Многосекционные термоэлементы, преимущества и проблемы их создания
}

\author{
(C) М.Ю. Штерн \\ Национальный исследовательский университет „МИЭТ“, \\ 124498 Москва, Зеленоград, Россия \\ E-mail: m.y.shtern@gmail.com
}

Поступила в Редакцию 12 августа 2021 г.

В окончательной редакции 28 августа 2021 r.

Принята к публикации 28 августа 2021 г.

\begin{abstract}
Рассмотрены пути повышения эффективности термоэлектрических генераторов. Наряду с повышением добротности термоэлектрических материалов это увеличение разности температур между горячими и холодными спаями термоэлементов и, соответственно, интервала их рабочих температур. Обоснована целесообразность использования термоэлементов с многосекционными ветвями. Для их создания предложены эффективные термоэлектрические материалы с рабочими температурами из интервала 300-1200 K. Разработана методика моделирования таких термоэлементов. Предложены структуры и материалы эффективных контактных систем для многосекционных термоэлементов, разработана технология их изготовления. Рассмотрены способы коммутации секций в ветвях термоэлемента. Исследовано тепловое расширение термоэлектрических материалов и предложен способ демпфирования термических напряжений в конструкции термоэлемента. Решена проблема сублимации термоэлектрического материала при высоких температурах за счет использования защитных покрытий.
\end{abstract}

Ключевые слова: термоэлектрические генераторы, многосекционные термоэлементы, термоэлектрические материалы, тепло- и электрофизические свойства, контактные системы, защитные покрытия.

DOI: 10.21883/FTP.2021.12.51690.02

\section{1. Введение}

Одно из основных современных научных направлений - создание альтернативных источников энергии и энергоэффективных технологий. Термоэлектричество может стать одной из таких альтернативных технологий. Тепловые насосы, работающие на эффекте Пельтье, перспективны для преобразования низкопотенциальной энергии земли и водных источников с целью отопления и кондиционирования зданий [1-3]. Термоэлектрические генераторы (ТЭГ) находят применение там, где требуются сверхнадежные источники электроэнергии, обладающие длительным сроком эксплуатации и не требующие обслуживания. Огромные возможности заключаются в использовании ТЭГ для преобразования „бросового“ тепла, доля которого в мировом производстве энергии составляет > 60\% [4-6]. Эффективность термоэлектрических преобразователей энергии определяется в основном эффективностью полупроводниковых материалов, используемых для изготовления термоэлементов. В результате интенсивного развития термоэлектричества в середине XX в. была достигнута эффективность термоэлектрических материалов (ТЭМ), определяемая их термоэлектрической добротностью $(Z)$ или безразмерным параметром $Z T$, значение которого не превышало 1.0. Однако, для того чтобы термоэлектрические устройства могли конкурировать с традиционными методами охлаждения и генерации электроэнергии, необходимо увеличить добротность ТЭМ в 2-3 раза. При этом отсутствуют какие-либо теоретические ограничения для увеличения ZT. В последние два десятилетия значительно выросла активность научных исследований в области термоэлектричества. Получены эффективные ТЭМ с параметром ZT, равным 1.2-1.4 [7-12]. Эти ТЭМ перекрывают практически весь рабочий интервал температур для термоэлектрических приборов от 150 до $1300 \mathrm{~K}$. В настоящее время активно ведутся исследования с целью получения наноструктурированных ТЭМ. Таким образом добиваются снижения фононной составляющей теплопроводности и, соответственно, увеличения $Z T[6,7,13-16]$.

Широкое применение ТЭГ сдерживается их низкой эффективностью. Коэффициент полезного действия современных ТЭГ, определяемый формулой (1), в лучшем случае составляет $8 \%$ :

$$
\eta=\frac{T_{H}-T_{C}}{T_{H}} \cdot \frac{\sqrt{(1+Z \bar{T})}-1}{\sqrt{(1+Z \bar{T})}+T_{C} / T_{H}},
$$

где $T_{H}$ и $T_{C}$ - температура горячих и холодных спаев термоэлементов соответственно; $\bar{T}=\left(T_{H}+T_{C}\right) / 2$.

Кпд генераторов в первую очередь зависит от добротности ТЭМ. Кроме того, кпд может быть увеличен за счет повышения разности температур $(\Delta T)$ между горячими и холодными спаями термоэлемента и, соответственно, расширения интервала рабочих температур ТЭГ. Для всех ТЭМ добротность имеет существенную температурную зависимость с наличием достаточно резкого максимума. Таким образом, максимальные значения добротности ТЭМ имеют в узком (ограниченном) интервале температур. Поэтому для создания 
эффективных ТЭГ необходимо использовать несколько различных ТЭМ. Конструктивно реализовать этот замысел возможно с помощью изготовления многосекционных термоэлементов (МТЭ). Каждая секция работает в определенном интервале температур и изготавливается из ТЭМ, имеющего максимальную $Z$ при этих температурах [8,17-23]. Однако создание МТЭ является сложнейшей конструкционно-технологической задачей, требующей решения ряда проблем. При конструировании МТЭ необходима оптимизация размеров каждой секции в ветвях термоэлемента. Кроме электрических параметров термоэлемента размеры секций, а именно их высота, определяет температурный интервал, в котором функционирует каждая секция. Одной из основных задач при изготовлении эффективных МТЭ является обеспечение качественного контакта секций. Для решения этой задачи необходима разработка технологии контактных систем (КС), состоящих из контактных слоев. Эти слои выполняют следующие функции: осуществляют омический контакт с ТЭМ; являются диффузионным барьером, предотвращающим взаимную диффузию соединяемых материалов; обеспечивают необходимую адгезию контактных слоев к ТЭМ. Необходимо отметить важность последней функции, так как эта адгезия является лимитирующим фактором в механической прочности термоэлемента. В технологии МТЭ необходимо получение термостабильных контактов, обладающих адгезионной прочностью не менее 8 МПа и контактным сопротивлением, не превышающим $10^{-8} \mathrm{OM} \cdot \mathrm{M}^{2}$ [2,15,17,23-29]. Существует несколько методов формирования КС. Перспективным является их получение вакуумным напылением $[19,23,27,30]$, которое обеспечивает минимальное значение контактного сопротивления и высокую адгезию. В конструкции МТЭ используются несколько ТЭМ с различным значением термического коэффициента линейного расширения (ТКЛР). Это осложняет ситуацию, так как в термоэлементе возникают существенные механические напряжения, которые могут привести к его разрушению. В этом плане целесообразным представляется создание структуры КС, которая, выполняя свои основные функции, дополнительно играла роль демпферного слоя. Еще одна проблема при конструировании высокотемпературных МТЭ, которая изучена ограниченно [31,32], - это сублимация ТЭМ при высоких температурах. Для таких температур необходима разработка и исследование защитных покрытий.

В связи с изложенным цель данной работы - определение путей решения проблем, связанных с созданием многосекционных термоэлементов для ТЭГ с рабочими температурами до $1200 \mathrm{~K}$.

\section{2. Методики исследования}

Для определения элементного состава полученных ТЭМ и контактных слоев использовался растровый электронный микроскоп JSM 6480LV фирмы JEOL с приставкой для энергодисперсионной рентгеновской спектрометрии INCA ENERGY Dry Cool. Предел относительной погрешности метода измерений не превышает 5\%.

Исследование термоэлектрических параметров ТЭМ осуществлялось с помощью разработанной методики и измерительного комплекса, представленных в работе [33]. Методика позволяет проводить исследования электропроводности, термоэдс и теплопроводности материалов в интервале 300-1200 К. Погрешности измерений составляют: электропроводности и термоэдс $3 \%$, теплопроводности - 5\%.

Шероховатость поверхности образцов, предназначенных для нанесения контактов, после механической обработки определяли с помощью профилометpa KLA-Tencor P-7. Этим же прибором измеряли толщину напыленных слоев $\mathrm{Ni}$ с погрешностью, не превышающей $5 \%$.

Измерение адгезионной прочности КС, формируемых на ТЭМ, проводилось методом прямого отрыва на установке Force Gauge PCE-FM50. Для этой цели с помощью фотолитографии формировали контакты площадью 1 мм² $^{2}$. Адгезионная прочность измерялась в значениях усилия отрыва на единицу площади (Па). Погрешность измерения не превышала 5\%.

Контактное сопротивление (КС) определялось с использованием разработанной авторами методики. В ее основе лежит измерение суммарного электрического сопротивления, состоящего из переходного контактного сопротивления и сопротивления ТЭМ, с последующим его исключением.

Для определения термической стабильности КС образцы подвергались отжигу в вакууме при их рабочих температурах в течение 60 мин. После термической обработки КС исследовались методом оже-электронной спектроскопии (ОЭС) на растровом оже-электронном спектрометре PHI-670ix с автоэмиссионым термокатодом Шоттки.

Оценка термической стабильности ТЭМ осуществлялась с помощью дифференциальной сканирующей калориметрии на калориметре Shimadzu DSC-50. Проводилось по 5 измерений каждого образца в атмосфере азота (20 мл/мин) со скоростью нагрева $10 \mathrm{~K}$ в мин.

Термогравиметрический анализ с целью исследования сублимирующего испарения ТЭМ проводился с помощью термоанализатора TA Instruments SDT Q600. Чувствительность прибора для определения изменения массы - 0.1 мкг. Скорость нагрева образцов составляла $10 \mathrm{~K}$ в мин. Измерения проводились на 5 образцах каждого ТЭМ.

Для исследования ТКЛР использовали дилатометрический метод, реализованный на базе кварцевых дилатометров. Для определения ТКЛР низкотемпературных ТЭМ использована методика, реализованная на базе термоэлектрического термостата [34]. Исследования ТКЛР проводились также на высокоточном горизонтальном 
дилатометре L75 PT с рабочим интервалом температур от 300 до $1700 \mathrm{~K}$.

\section{3. Экспериментальная часть и обсуждение}

\section{1. Термоэлектрические материалы}

Для МТЭ с рабочими температурами от 300 до $1200 \mathrm{~K}$ получены эффективные ТЭМ. С помощью энергодисперсионной рентгеновской спектрометрии определен химический состав полученных ТЭМ. Проведены исследования температурных зависимостей термоэлектрических параметров ТЭМ. По полученным данным проведен расчет $Z$ и безразмерного параметра $Z T$, температурные зависимости которого представлены на рис. 1. Результаты температурной зависимости $Z T$ позволяют определить интервалы рабочих температур ТЭМ, где они имеют максимальные значения $Z T$.

Для температур до $400 \mathrm{~K}$ методом зонной плавки изготовлены $\mathrm{Bi}_{2} \mathrm{Te}_{2.8} \mathrm{Se}_{0.2}\left(0.14 \mathrm{Mac} \% \mathrm{CdCl}_{2}\right) \quad n$-типа и $\mathrm{Bi}_{0.5} \mathrm{Sb}_{1.5} \mathrm{Te}_{3}$ (2 мac\% Te, 0.14 мac\% $\%^{\mathrm{TeI}_{4}}$ ) $p$-типа проводимости с максимальными $Z T$, равными 1.05 и 1.11 соответственно.

Для интервала температур 400-600 K методом экструзии получены $\mathrm{Bi}_{2} \mathrm{Te}_{2.4} \mathrm{Se}_{0.6}(0.18 \mathrm{mac} \% \mathrm{CuBr}) n$-типа и $\mathrm{Bi}_{0.4} \mathrm{Sb}_{1.6} \mathrm{Te}_{3}\left(0.12 \mathrm{Mac} \% \mathrm{PbCl}_{2}, 1.50\right.$ мас\% $\left.\% \mathrm{Te}\right) p$-типа с максимальными $Z T$, равными 1.19 и 1.20 соответственно. В интервале температур $600-900 \mathrm{~K}$ максимальные значения $Z T$, равные 1.08 и 1.20 , имеют $\mathrm{PbTe}(0.2 \mathrm{мac} \%$ $\left.\mathrm{PbI}_{2}, 0.3 \mathrm{Mac} \% \mathrm{Ni}\right) n$-типа и $\mathrm{GeTe}(7.4 \mathrm{Mac} \% \mathrm{Bi}) p$-типа соответственно. Эти материалы получены методом горячего прессования. Для рабочих температур 900-1200 K методом искрового плазменного спекания получены материалы $n$ - и $p$-типа: $\mathrm{Si}_{0.8} \mathrm{Ge}_{0.2}$ (2.2 мас\% $\mathrm{P}$ ) и $\mathrm{Si}_{0.8} \mathrm{Ge}_{0.2}$ $(1.8$ мас\% В), с максимальными $Z T$, равными 1.04 и 1.03 соответственно.

\section{2. Моделирование многосекционного термоэлемента}

Как указано выше, максимальная эффективность МТЭ будет в том случае, если каждая секция и, соответственно, ТЭМ, из которого она изготовлена, функционируют в интервале температур, где $Z T$ имеет высокие значения (рис. 1). Для этого необходимо оптимизировать конструкцию МТЭ. С этой целью разработана методика моделирования МТЭ и программное обеспечение (ПО) для ее реализации. При моделировании конструкции МТЭ основными данными являются тепло- и электрофизические параметры ТЭМ и их температурные зависимости. Граничные условия моделирования: температуры горячих $\left(T_{H}\right)$ и холодных $\left(T_{C}\right)$ спаев и разность температур $\left(\Delta T=T_{H}-T_{C}\right)$, а также максимально допустимая высота термоэлемента. В результате моделирования определяется оптимальная высота секций

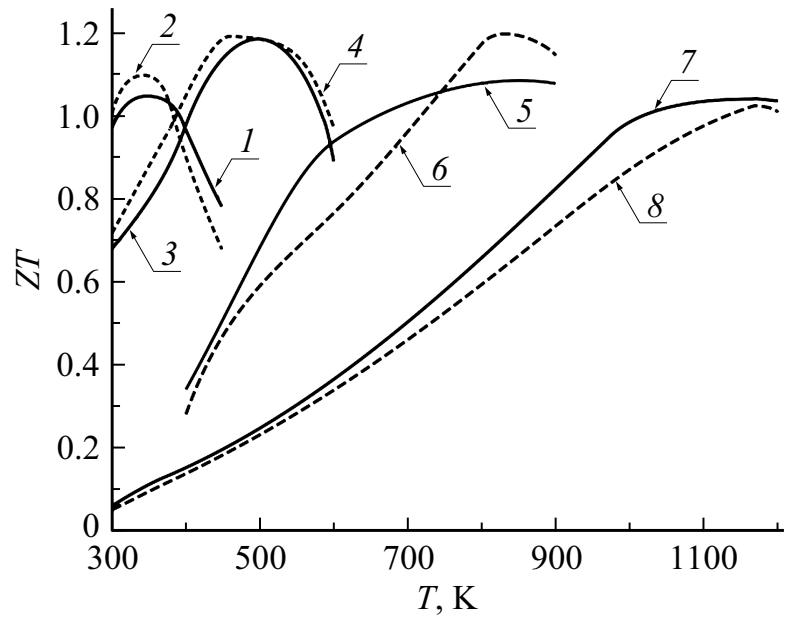

Рис. 1. Температурные зависимости параметра $Z T$ ТЭМ. $1-\mathrm{Bi}_{2} \mathrm{Te}_{2.8} \mathrm{Se}_{0.2}, 2-\mathrm{Bi}_{0.5} \mathrm{Sb}_{1.5} \mathrm{Te}_{3}, 3-\mathrm{Bi}_{2} \mathrm{Te}_{2.4} \mathrm{Se}_{0.6}$, $4-\mathrm{Bi}_{0.4} \mathrm{Sb}_{1.6} \mathrm{Te}_{3}, 5-\mathrm{PbTe}, 6-\mathrm{GeTe}, 7-\mathrm{Si}_{0.8} \mathrm{Ge}_{0.2}$ (n-тип), $8-\mathrm{Si}_{0.8} \mathrm{Ge}_{0.2}$ (р-тип).

в ветвях МТЭ, при которой ТЭМ имеет максимальные $Z T$, что в итоге позволяет получить максимальные значения кпд для МТЭ. Оптимизация конструкции МТЭ осуществляется следующим образом. Высота каждой секции $\left(l_{n i}, l_{p j}\right)$ зависит от интервала рабочих температур секций $\left(T_{n i}-T_{n i-1}, T_{p j}-T_{p j-1}\right)$ и коэффициентов теплопроводности ТЭМ $\left(\kappa_{n i}, \kappa_{p j}\right)$, где $i, j-$ номера секций для ветвей $n$ - и $p$-типов. Вначале, по экспериментальным данным, производится расчет средних значений коэффициентов термоэдс $(\bar{s})$, электропроводности $(\bar{\sigma})$ и теплопроводности $(\bar{\kappa})$ для каждой секции в рабочем интервале температур. Далее определяется высота каждой секции. Расчет основывается на том, что тепловой поток, проходящий от горячего спая к холодному через каждую секцию, имеет постоянное значение:

$$
\begin{gathered}
\frac{\bar{\kappa}_{n 1} \Delta T_{n 1}}{l_{n 1}}=\frac{\bar{\kappa}_{n i} \Delta T_{n i}}{l_{n i}}=\ldots=\frac{\bar{\kappa}_{n N} \Delta T_{n N}}{l_{n N}} ; \\
\frac{\bar{\kappa}_{p 1} \Delta T_{p 1}}{l_{p 1}}=\frac{\bar{\kappa}_{p j} \Delta T_{p j}}{l_{p j}}=\ldots=\frac{\bar{\kappa}_{p P} \Delta T_{n P}}{l_{p P}},
\end{gathered}
$$

где $\Delta T_{n i}$ и $\Delta T_{p j}$ - разница температур на $i$ и $j$ секциях $n$ - и $p$-ветвей; $N$ и $P$ - количество секций $n$ - и $p$-ветвей; $\bar{\kappa}_{n i}$ и $\bar{\kappa}_{p j}$ - усредненное значение коэффициента теплопроводности в интервале рабочих температур $i$ и $j$ секций.

Суммы высот секций $n$ - и $p$-ветвей должны быть равны между собой и соответствовать заданному размеру ветвей МТЭ. То же самое касается и разницы температур между горячим и холодным спаями МТЭ:

$$
L_{n, p}=\sum_{i=1}^{N} l_{i}=\sum_{j=1}^{P} l_{j} ; \quad \Delta T=\sum_{i=1}^{N} \Delta T_{n i}=\sum_{j=1}^{P} \Delta T_{p j} .
$$

Профиль температуры ветвей МТЭ определяется $\bar{\kappa}_{n i}$ и $\bar{\kappa}_{p j}$. Данные по теплопроводности получены в результате 


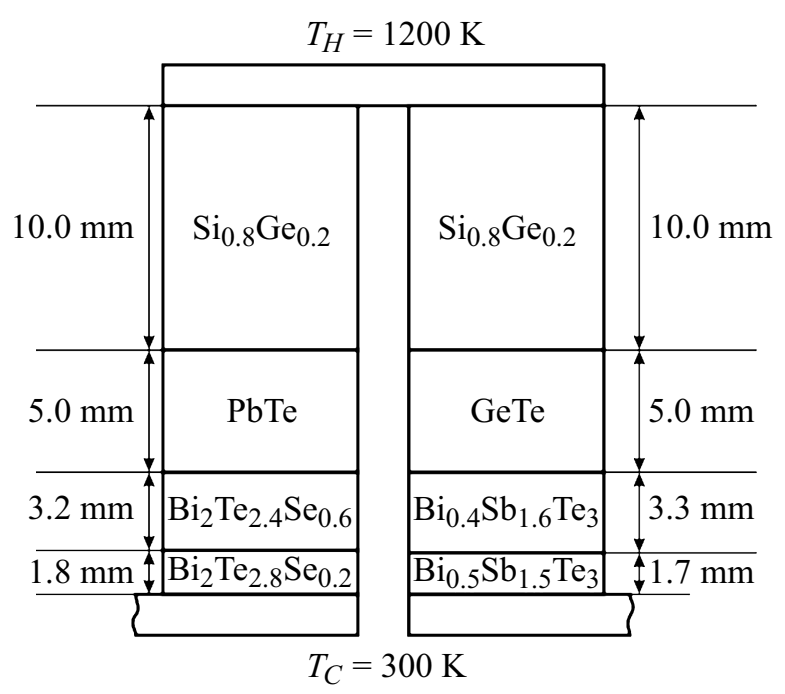

Рис. 2. Конструкция многосекционного термоэлемента.

исследований ТЭМ. Кроме того, известны интервалы температур, в которых наблюдаются максимальные значения $Z T$ (рис. 1). В связи с этим из уравнений (3) можно рассчитать высоту $i$ или $j$ секции следующим образом:

$$
l_{n i}=\frac{L_{p, n} \bar{\kappa}_{n i} \Delta T_{n i}}{\bar{\kappa}_{n} \Delta T} ; l_{p j}=\frac{L_{p, n} \bar{\kappa}_{p j} \Delta T_{p j}}{\bar{\kappa}_{p} \Delta T} .
$$

В результате моделирования МТЭ с использованием граничных условий $\left(T_{H}=1200 \mathrm{~K} ; T_{C}=300 \mathrm{~K}\right.$; максимальная высота ветвей МТЭ - 20 мм) получена конструкция МТЭ, представленная на рис. 2.

Разработанная методика ориентирована на получение максимального кпд. Для МТЭ, представленного на рис. 2, кпд без учета тепловых и электрических потерь на контактах, составляет 21.5\%. Это согласуется с данными [17,35]. Расчетное значение кпд для термоэлемента, изготовленного из ТЭМ на основе $\mathrm{Si}_{0.8} \mathrm{Ge}_{0.2}$ при $\Delta T=900 \mathrm{~K}$, без учета потерь составляет $12 \%$. Это подтверждает целесообразность конструирования МТЭ.

\section{3. Контактные системы}

Получение качественных контактных систем является основной проблемой при создании МТЭ. Для формирования контактных слоев в КС использовали методы вакуумного напыления в совокупности с химическим осаждением коммутационных слоев. Состояние поверхности ТЭМ, на которых формируются КС, является решающим фактором для их адгезии, а также оказывает существенное влияние на контактное сопротивление. Перед формированием КС поверхность ТЭМ подвергалась механической обработке по методике [19]. Важно получить заданную шероховатость поверхности, которая существенно влияет на адгезию пленки. При шероховатости, соизмеримой с толщиной пленки, возможны ее разрывы и, как следствие, снижение адгезии и увеличение электрического сопротивления контактов [23]. В качестве первых слоев КС использовались пленки толщиной 300 нм и выше. Поэтому поверхность ТЭМ обрабатывалась с шероховатостью, не превышающей 200 нм. Перед загрузкой в камеру напылительной системы образцы промывались в изопропиловом спирте с последующей сушкой в потоке азота. Непосредственно в камере производился вакуумно-термический отжиг образцов при начальном давлении $7 \cdot 10^{-8}$ Торр и температуре $473 \mathrm{~K}$. После отжига проводилась очистка поверхности образцов бомбардировкой ионами аргона в течение 30 с. Контакты могут быть изготовлены из одного материала, например $\mathrm{Ni}$ или Сo, что возможно при низких температурах [23,27]. Однако, при повышенных температурах, что характерно для МТЭ, необходимо применение КС, состоящих из нескольких контактных слоев. В этом случае каждый слой в структуре КС выполняет свои функции, о которых было указано выше. Первый слой в структуре КС, который формируется непосредственно на ТЭМ, должен обеспечивать омический контакт с ТЭМ. Этот слой определяет в основном и адгезионную прочность контакта. Необходимым условием существования омического контакта на границе металл-полупроводник является низкое значение барьера Шоттки. Барьер Шоттки определяется двумя механизмами проводимости: термоэлектронной эмиссией и туннелированием [36]. Для большинства полупроводников экспериментально было обнаружено, что энергетический барьер не зависит от работы выхода металла, а определяется плотностью поверхностных со стояний [36-38]. В связи с этим широко используется способ изготовления омических контактов - сильное легирование полупроводника у контакта. Преобладающая туннельная компонента тока экспоненциально зависит от концентрации свободных носителей тока [37]. При концентрации $\sim 10^{19} \mathrm{~cm}^{-3}$ сопротивление контакта определяется в основном туннельными процессами. Необходимо отметить этот положительный эффект для ТЭМ, имеющих концентрацию носителей, как правило, превышающую $10^{19} \mathrm{~cm}^{-3}$.

Для обеспечения омического контакта необходимо использовать материалы контактных слоев с низким удельным сопротивлением, например Мо, W, Со и Ni [23]. Для низких температур хорошо зарекомендовал себя $\mathrm{Ni}$, получаемый вакуумным напылением $[19,27,28,39]$. Проведенные исследования методом ОЭС образцов с контактами из $\mathrm{Ni}$ толщиной 400-500 нм после термической обработки в вакууме при $577 \mathrm{~K}$ показали, что при этой температуре Ni перестает выполнять функции барьерного слоя [23,27]. Таким образом, никелевые контакты целесообразно использовать при температурах до 500 K. Выше этой температуры Ni можно использовать в комбинации, например, с Мо [23,27].

Для термоэлементов, работающих при повышенных температурах, в структуре КС необходимо использовать диффузионно-барьерный слой (ДБС). В работе [23] на 
основании физико-химического анализа причин стабильности и деградации ДБС нами обоснованы критерии и определены материалы ДБС, обеспечивающие высокую температурную стабильность КС. Наиболее перспективными для ДБС являются такие материалы, как $\mathrm{Mo}, \mathrm{Nb}$, $\mathrm{Ta}, \mathrm{W}$. При высоких температурах в качестве ДБС целесообразно использование аморфных материалов [23]. В качестве аморфного слоя в КС использовали пленки сплава Ta-W-N, сформированные методом магнетронного распыления. Таким образом, согласно определенным выше критериям выбраны следующие структуры и материалы слоев КС. Никелевые пленки толщиной до 400 нм использовались при температурах до $500 \mathrm{~K}$.

Выше этой температуры применяли двухслойную КС $\mathrm{Mo} / \mathrm{Ni}$. Слой Мо толщиной 300-400 нм обеспечивал низкоомный контакт и адгезию КС к ТЭМ, а также являлся ДБС. Слой Ni толщиной до 400 нм использовался как коммутационный слой. При высоких температурах целесообразно использовать КС Mo/Ta-W-N/Ni. Слой Ta-W-N толщиной 400 нм, дополнительно к барьерным функциям Мо, существенно усиливал ДБС.

Напыление контактных слоев КС осуществлялось в едином вакуумном цикле на установке ионно-плазменного напыления УРМ 3.279.026, оснащенной двумя магнетронными системами. Формирование КС на основе $\mathrm{Ni}$ осуществлялось путем распыления мишени Ni. Нанесение $\mathrm{KC} \mathrm{Mo} / \mathrm{Ni}$ проводилось путем последовательного распыления, сначала мишени Мо, потом Ni. Формирование трехслойной КС $\mathrm{Mo} / \mathrm{Ta}-\mathrm{W}-\mathrm{N} / \mathrm{Ni}$ осуществлялось путем последовательного распыления сначала мишени Мо в среде аргона, затем мозаичной мишени Тa-W в среде смеси газов аргона и азота.

Каждая ветвь МТЭ состоит из четырех секций, изготавливаемых из различных ТЭМ (рис. 2). На ТЭМ, с учетом их рабочих температур, формировались КС, представленные в табл. 1.

Проведены измерения адгезионной прочности и удельного контактного сопротивления КС, сформированных

Таблица 1. Образцы ТЭМ и структуры сформированных на них КС

\begin{tabular}{|c|c|c|}
\hline № & Образцы ТЭМ & Структура КС \\
\hline 1 & $\mathrm{Bi}_{2} \mathrm{Te}_{2.8} \mathrm{Se}_{0.2}$ & $\mathrm{Ni}(400$ нм $)$ \\
\hline 2 & $\mathrm{Bi}_{0.5} \mathrm{Sb}_{1.5} \mathrm{Te}_{3}$ & $\mathrm{Ni}(400$ нм $)$ \\
\hline 3 & $\mathrm{Bi}_{0.4} \mathrm{Sb}_{1.6} \mathrm{Te}_{3}$ & Мо $(300$ нм $) / \mathrm{Ni}(400$ нм $)$ \\
\hline 4 & $\mathrm{Bi}_{2} \mathrm{Te}_{2.4} \mathrm{Se}_{0.6}$ & Мо $(300$ нм $) / \mathrm{Ni}(400$ нм $)$ \\
\hline 5 & $\begin{array}{l}\operatorname{PbTe}(600 \mathrm{~K}) \\
\operatorname{PbTe}(850 \mathrm{~K})\end{array}$ & $\begin{array}{l}\text { Mo }(400 \text { нм }) / \mathrm{Ni}(400 \mathrm{нм}) \\
\text { Mo }(400 \mathrm{нм}) / \mathrm{Ta}-W-N(400 \mathrm{Hм}) / \mathrm{Ni}(400 \mathrm{Hм})\end{array}$ \\
\hline 6 & $\begin{array}{l}\operatorname{GeTe}(600 \mathrm{~K}) \\
\operatorname{GeTe}(850 \mathrm{~K})\end{array}$ & $\begin{array}{l}\text { Mo }(400 \mathrm{Hм}) / \mathrm{Ni}(400 \mathrm{Hм}) \\
\text { Mo }(400 \mathrm{Hм}) / \mathrm{Ta}-\mathrm{W}-\mathrm{N}(400 \mathrm{Hм}) / \mathrm{Ni}(400 \mathrm{Hм})\end{array}$ \\
\hline 7 & $\mathrm{Si}_{0.8} \mathrm{Ge}_{0.2}(\mathrm{P})$ & Мо (400 нм $) / \mathrm{Ta}-\mathrm{W}-\mathrm{N}$ (400 нм)/Ni (400 нм) \\
\hline 8 & $\mathrm{Si}_{0.8} \mathrm{Ge}_{0.2}(\mathrm{~B})$ & Мо (400 нм)/Ta-W-N (400 нм)/Ni (400 нм) \\
\hline
\end{tabular}

Таблица 2. Адгезионная прочность и удельное сопротивление КС

\begin{tabular}{l|c|c}
\hline Образцы ТЭМ & $\begin{array}{c}\text { Адгезионная } \\
\text { прочность } \\
\text { КС, МПа }\end{array}$ & $\begin{array}{c}\text { Удельное } \\
\text { сопротивление } \\
\text { контакта, Ом } \mathrm{M}^{2}\end{array}$ \\
\hline $\mathrm{Bi}_{2} \mathrm{Te}_{2.8} \mathrm{Se}_{0.2}$ & 15.72 & $0.8 \cdot 10^{-9}$ \\
$\mathrm{Bi}_{0.5} \mathrm{Sb}_{1.5} \mathrm{Te}_{3}$ & 15.64 & $0.9 \cdot 10^{-9}$ \\
$\mathrm{Bi}_{0.4} \mathrm{Sb}_{1.6} \mathrm{Te}_{3}$ & 14.56 & $0.9 \cdot 10^{-9}$ \\
$\mathrm{Bi}_{2} \mathrm{Te}_{2.4} \mathrm{Se}_{0.6}$ & 14.42 & $1.0 \cdot 10^{-9}$ \\
$\mathrm{PbTe}(600 \mathrm{~K})$ & 14.12 & $1.1 \cdot 10^{-9}$ \\
$\mathrm{PbTe}(850 \mathrm{~K})$ & 14.08 & $1.3 \cdot 10^{-9}$ \\
$\mathrm{GeTe}(600 \mathrm{~K})$ & 14.24 & $1.1 \cdot 10^{-9}$ \\
$\mathrm{GeTe}(850 \mathrm{~K})$ & 14.20 & $1.4 \cdot 10^{-9}$ \\
$\mathrm{Si}_{0.8} \mathrm{Ge}_{0.2}(\mathrm{P})$ & 14.73 & $1.5 \cdot 10^{-9}$ \\
$\mathrm{Si}_{0.8} \mathrm{Ge}_{0.2}(\mathrm{~B})$ & 14.64 & $1.5 \cdot 10^{-9}$
\end{tabular}

на ТЭМ, указанных в табл. 1. На всех образцах разрушение контакта осуществлялось по границе ТЭМ-КС. Результаты измерений представлены в табл. 2.

На ТЭМ, работающих при температурах до $400 \mathrm{~K}$ (рис. 2), формировали однослойные никелевые КС толщиной 400 нм. Полученные КС имели хорошую адгезионную прочность, превышающую 15 МПа, и низкое удельное контактное сопротивление $\sim 10^{-9} \mathrm{OM} \cdot \mathrm{M}^{2}$. На ТЭМ, работающих при температурах до $600 \mathrm{~K}$, в качестве барьерного слоя использовали Мо толщиной 300-400 нм. Коммутационный слой Ni напыляли толщиной 400 нм. Такие КС формировали на образцах $\mathrm{Bi}_{0.4} \mathrm{Sb}_{1.6} \mathrm{Te}_{3}$ и $\mathrm{Bi}_{2} \mathrm{Te}_{2.4} \mathrm{Se}_{0.6}$, а также на образцах $\mathrm{PbTe}$ и GeTe при их рабочих температурах до $850 \mathrm{~K}$. Адгезионная прочность полученных КС уменьшилась незначительно (на 6-7\%). Изменение контактного сопротивления КС в пределах погрешности измерений. Для температур $850 \mathrm{~K}$ и выше на образцах $\mathrm{PbTe}$ и GeTe и образцах на основе $\mathrm{Si}_{0.8} \mathrm{Ge}_{0.2}$ усилили ДБС введением в состав КС аморфного слоя Ta-W-N толщиной 400 нм. Для полученных КС адгезионная прочность практически не изменилась. При этом наблюдается некоторое увеличение контактного сопротивления за счет аморфного слоя (табл. 2).

Для исследований термической стабильности КС образцы подвергались отжигу в вакууме при рабочих температурах каждого ТЭМ в течение 60 мин. После этого с помощью оже-электронной спектроскопии было проведено исследование ОЭС-профиля распределения элементов по глубине КС. При этом использовалось послойное ионное распыление поверхности образцов. В качестве примера результатов исследований приведены ОЭС-профили распределения элементов по глубине $\sim 900$ нм от поверхности образцов $\mathrm{GeTe}$ и $\mathrm{PbTe}$ (рис. 3).

Для исследования термической стабильности КС-Mo (400 нм)/Ni (400 нм) образцы были подвергнуты отжигу в вакууме при $800 \mathrm{~K}$ в течение 60 мин. На 

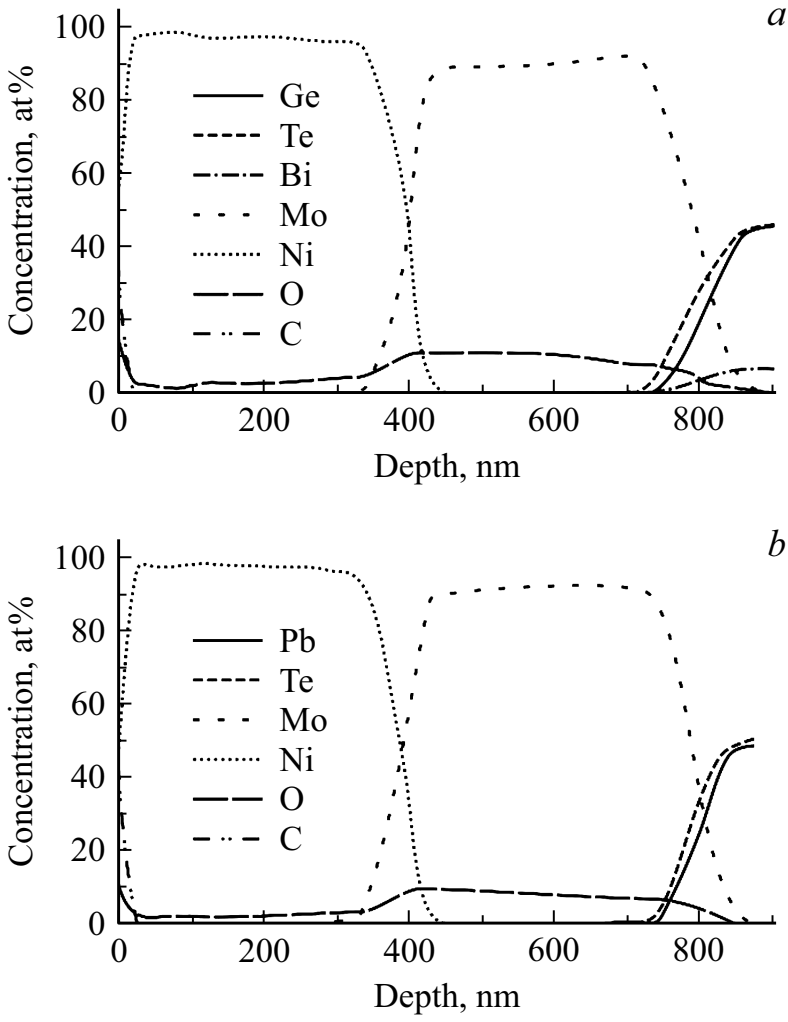

Рис. 3. ОЭС-профили распределения элементов по глубине образцов: $a-\mathrm{GeTe}+\mathrm{Mo}(400$ нм $)+\mathrm{Ni}(400$ нм $) ; b-$ $\mathrm{PbTe}+\mathrm{Mo}(400 \mathrm{Hм})+\mathrm{Ni}(400 \mathrm{Hм})$.

рисунке хорошо видны ярко выраженные слои $\mathrm{Ni}$ толщиной $\sim 400$ нм и слои Мо $(400 \mathrm{Hм})$, нанесенного непосредственно на ТЭМ. Важно отметить отсутствие проникновения элементов ТЭМ через ДБС из Мо. Таким образом, можно сделать вывод, что КС являются термостабильными при температурах до $800 \mathrm{~K}$.

Также проведены исследования ОЭС-профилей распределения элементов по глубине на других ТЭМ с КС, представленных в табл. 1. Результаты исследования показали термостабильность КС.

\section{4. Коммутация термоэлемента}

Для коммутации секций в МТЭ требуется повышенная толщина коммутационного слоя. С этой целью было использовано химическое осаждение $\mathrm{Ni}$ на представленные выше КС. Осаждение проводили из борогидридного электролита при температурах $360 \mathrm{~K}$ в течение 60 мин. Толщина осажденных пленок составляла 17-20мкм. С помощью энергодисперсионной рентгеновской спектрометрии определен химический состав полученных пленок, в котором обнаружено $\mathrm{Ni}-96.84$ мас\%. Основные другие элементы: C - 1.85 мас\%, О - 1.17 мас\%.

Коммутация секций в структуре МТЭ осуществлялась несколькими способами. Коммутация низкотемпературных секций в ветвях МТЭ проводилась с помощью пайки. При повышенных температурах, кроме высокотемпературной пайки, для коммутации использовали способы, реализуемые посредством: образования сплава $\mathrm{Ni}-\mathrm{In}$, эвтектического сплава $\mathrm{Ni}-\mathrm{Sn}$, использования бондинга слоев Au-Au.

Коммутация секций с помощью интерметаллического соединения Ni-In проводилась следующим образом. На соединяемых поверхностях на слое $\mathrm{Ni}$ формировали слой гальванического In толщиной 2 мкм в гальваностатическом режиме в электролите на основе $\mathrm{In}_{2}\left(\mathrm{SO}_{4}\right)_{3}$ и $\mathrm{Na}_{2} \mathrm{SO}_{4}$ при температуре $300 \mathrm{~K}$. Сращивание секций проводили под давлением при $570 \mathrm{~K}$ с последующим увеличением температуры до $670 \mathrm{~K}$ в течение 30 мин. Для соединения секций с помощью эвтектического сплава Ni-Sn на никелевом слое КС формировали слой олова толщиной 2 мкм вакуумным термическим испарением на установке УВН71Р-1. Сращивание секций проводилось под давлением в боксе с инертной средой при температуре $600 \mathrm{~K}$ в течение 30 мин.

Перспективным способом коммутации секций является бондинг, обеспечивающий сращивание коммутационных слоев $\mathrm{Au}-\mathrm{Au}$. Для проведения операций бондирования на поверхности коммутационного слоя $\mathrm{Ni}$ в КС формировали слои V (50 нм) и Аu (500 нм). Осаждение указанных слоев проводили на установке электронного напыления металлов фирмы Kurt J. Lesker при давлении в вакуумной камере не выше $7.5 \cdot 10^{-7}$ Па и ускоряющем напряжение $10^{4}-10^{5}$ Вт/см. Операцию бондинга проводили на установке SUSS MicroTec FC150 FLIP CHIP BONDER, при следующих режимах: температура $610 \mathrm{~K}$, усилие сдавливания соединяемых секций до $850 \mathrm{H}$, время 25 мин. Для определения качества соединений секций в МТЭ на основе теллуридов свинца и германия с секциями на основе $\mathrm{SiGe}$ использовали метод прямого отрыва. Разрушение соединений происходило при нагрузках больше $14 \mathrm{MПа} \mathrm{по} \mathrm{границе} \mathrm{ТЭМ-КС.} \mathrm{Таким}$ образом, механическая прочность соединения секций определялась адгезионной прочностью КС. Коммутация, формируемая с помощью бондинга, не нарушалась.

\section{5. Тепловое расширение материалов}

С помощью кварцевых дилатометров различной конструкции исследовано тепловое расширение разработанных ТЭМ в области температур 200-1200 К. Среднее значение ТКЛР определялось по формуле [40]

$$
\bar{\alpha}=\left(L_{T}-L_{0}\right) /\left(L_{0} \cdot\left(T-T_{0}\right)\right),
$$

где $L_{T}$ - значение длины образца при конечной температуре, $L_{0}$ - значение длины образца при температуpe $T_{0}$.

Вычисленное таким образом среднее значение ТКЛР относится к конечной температуре интервала $(T)$. Результаты исследования ТКЛР ТЭМ $n$ - и $p$-типа проводимости представлены на рис. 4. В результате исследования низкотемпературных ТЭМ в интервале 

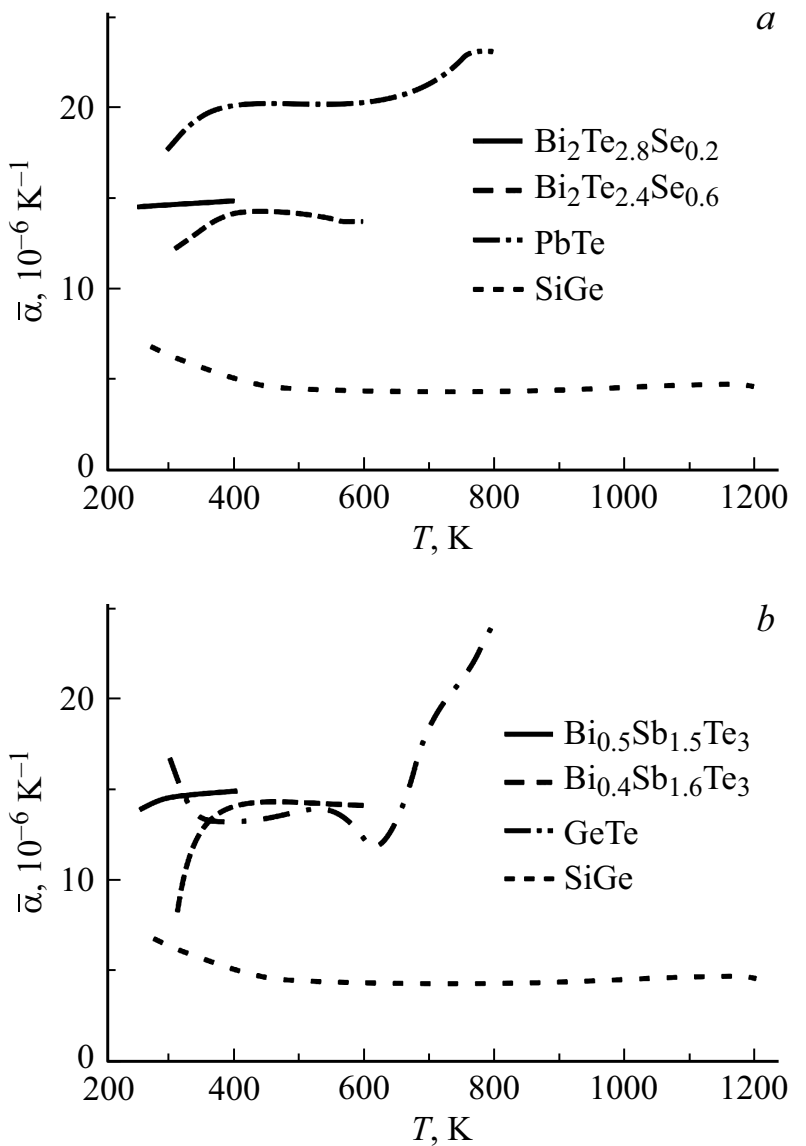

Рис. 4. Температурные зависимости ТКЛР ТЭМ $n$-типа $(a)$ и $p$-типа $(b)$.

$200-400 \mathrm{~K}$ среднее значение ТКЛР $\mathrm{Bi}_{2} \mathrm{Te}_{2.8} \mathrm{Se}_{0.2}$ изменяется от $14.5 \cdot 10^{-6}$ до $14.8 \cdot 10^{-6} \mathrm{~K}^{-1}$, а $\mathrm{Bi}_{0.5} \mathrm{Sb}_{1.5} \mathrm{Te}_{3}-$ от $13.9 \cdot 10^{-6}$ до $15.0 \cdot 10^{-6} \mathrm{~K}^{-1}$. Таким образом, ТКЛР этих материалов имеют близкие значения. Для среднетемпературных ТЭМ $\mathrm{Bi}_{2} \mathrm{Te}_{2.4} \mathrm{Se}_{0.6}$ и $\mathrm{Bi}_{0.4} \mathrm{Sb}_{1.6} \mathrm{Te}_{3}$ исследования проводились в интервале температур от 300 до $600 \mathrm{~K}$. ТКЛР рассматриваемых материалов после $350 \mathrm{~K}$ имеет практически постоянное значение на уровне $(13.93-14.33) \cdot 10^{-6} \mathrm{~K}^{-1}$. Близкие значения ТКЛР для теллуридов висмута и сурьмы были получены в работе [25].

Значения ТКЛР РbТе в интервале $600-900 \mathrm{~K}$ изменяются от $20.14 \cdot 10^{-6}$ до $23.07 \cdot 10^{-6} \mathrm{~K}^{-1}$ при $900 \mathrm{~K}$. Похожие значения ТКЛР были получены в работах $[41,42]$. Для $\mathrm{GeTe}$ резкое увеличение ТКЛР в области температур $620-680 \mathrm{~K}$ связано с изменением структуры при этих температурах с ромбоэдрической на кубическую типа $\mathrm{NaCl}$, которое описано в работах $[43,44]$. В дальнейшем с ростом температуры ТКЛР увеличивается, достигая $24.47 \cdot 10^{-6} \mathrm{~K}^{-1}$ при $900 \mathrm{~K}$. При максимальных рабочих температурах ТКЛР $\mathrm{PbTe}$ и GeTe различаются не существенно. Представленные результаты совпадают с рентгеновскими данными, полученными другими авторами: $\mathrm{PbTe}[41]$ и GeTe [43].
Тепловое расширение высокотемпературных ТЭМ на основе $\mathrm{SiGe}$ изучено крайне ограниченно дилатометрическим методом [45] и на основе рентгенографических данных [46]. Как и следовало ожидать, температурные зависимости ТКЛР $\mathrm{SiGe} n$ - и $p$-типов проводимости практически не отличаются (рис. 4). С ростом температуры ТКЛР уменьшается с $7 \cdot 10^{-6}(300 \mathrm{~K})$ до $4.5 \cdot 10^{-6} \mathrm{~K}^{-1}$ при $500 \mathrm{~K}$. Далее с температурой ТКЛР увеличивается незначительно, достигая максимального значения $4.8 \cdot 10^{-6} \mathrm{~K}^{-1}$ при $1180 \mathrm{~K}$. Выше этой температуры наблюдается аномалия, связанная с тенденцией к снижению ТКЛР. Полученные результаты по ТКЛР согласуются с данными для чистого кремния [47].

Анализируя результаты исследования ТКЛР, необходимо отметить, что ТКЛР материалов на основе $\mathrm{PbTe}$ и $\mathrm{GeTe}$ существенно различается с ТКЛP SiGe. В области температур $900 \mathrm{~K}$, при которых осуществляется контакт секций, изготовленных из этих материалов, ТКЛР различаются в 6 раз. Это требует принятия конструкционных решений, обеспечивающих демпфирование механических напряжений, возникающих в процессе термоциклирования МТЭ. С этой целью нами предлагается на секциях, существенно различающихся по ТКЛР, формировать в структуре КС слой из композиционного материала следующим образом. На сформированной структуре КС методом химического осаждения из газовой фазы выращивается массив углеродных нанотрубок при температуре $820 \mathrm{~K}$ в течение 5 мин. После этого методом химического осаждения из раствора соли никеля осаждается металлический никель, являющийся проводящим материалом. $\mathrm{Ni}$ заполняет пространство между углеродными нанотрубками. На завершающей стадии проводится термообработка структуры в вакууме при температуре $920 \mathrm{~K}$ в течение 60 мин. В результате никель смачивает углеродные нанотрубки и затекает между ними, образуя композиционный проводящий материал. Полученная таким образом КС увеличивает механическую прочность и повышает термическую стойкость термоэлемента [48].

\section{6. Термическая стабильность материалов}

Оценка термической стабильности исследуемых ТЭМ при термоциклировании проведена с помощью методов дифференциальной сканирующей калориметрии и термогравиметрии. Исследования $\mathrm{Bi}_{2} \mathrm{Te}_{2.8} \mathrm{Se}_{0.2}$, $\mathrm{Bi}_{0.5} \mathrm{Sb}_{1.5} \mathrm{Te}_{3}, \mathrm{Bi}_{2} \mathrm{Te}_{2.4} \mathrm{Se}_{0.6}, \mathrm{Bi}_{0.4} \mathrm{Sb}_{1.6} \mathrm{Te}_{3}$ проводились в интервале температур $300-600 \mathrm{~K}$. На полученных ДСК кривых не наблюдалось тепловых эффектов с увеличением температуры от 300 до $600 \mathrm{~K}$, обусловленных фазовыми переходами. Результаты получены для всех указанных ТЭМ независимо от состава и способов их получения. С помощью термогравиметрии оценивалось изменение массы ТЭМ. Исследования показали, что увеличение температуры не приводит к существенному изменению массы образцов для всех ТЭМ при температурах $300-600 \mathrm{~K}$. Отсутствие заметного изменения веса 
при термоциклировании свидетельствует о том, что в исследованном температурном диапазоне не наблюдается сублимации и окисления ТЭМ.

Термическую стабильность ТЭМ на основе РbТе и GeTe исследовали в интервале температур 300-900 K и ТЭМ на основе $\mathrm{SiGe} n$ - и $p$-типа в интервале $300-1200$ K. На полученных ДСК кривых не наблюдалось явных тепловых эффектов во всем температурном интервале измерений. Таким образом, можно отметить, что исследуемые материалы являются термически стабильными в указанных интервалах температур для каждого ТЭМ. При исследовании с помощью термогравиметрии сублимации и окисления в рабочих интервалах температур наблюдали следующее. Для ТЭМ на основе $\mathrm{SiGe}$ масса образцов несущественно уменьшается вплоть до температуры $1200 \mathrm{~K}$. Выше температуры $850 \mathrm{~K}$ для $\mathrm{PbTe}$ и GeTe начинается резкое уменьшение массы образцов, что свидетельствует о начале сублимации этих материалов. Результаты исследований показывают, что при выборе диапазона рабочих температур ТЭМ необходимо учитывать не только температурные зависимости их термоэлектрических параметров, но и термическую стабильность материалов. Например, для $\mathrm{PbTe}$ и GeTe верхний диапазон рабочих температур должен быть ограничен $850 \mathrm{~K}$.

Для исключения негативных процессов окисления и сублимации целесообразно использование защитных покрытий для термоэлементов. С помощью этого приема возможно увеличение интервала рабочих температур. В качестве защитных покрытий исследовались слои $\mathrm{Si}_{3} \mathrm{~N}_{4}$ и $\mathrm{SiO}_{2}$. Нанесение этих слоев осуществлялось плазмохимическим методом (установка CORIAL D250), толщины слоев составляли 1.0 и 0.25 мкм соответственно. Формирование защитных покрытий производилось при температуре $520 \mathrm{~K}$. Исследования с помощью термогравиметрии показали эффективность указанных защитных покрытий до температуры $1200 \mathrm{~K}$.

\section{4. Заключение}

Разработаны эффективные ТЭМ для интервала рабочих температур 200-1200 K с добротностью ZT от 1.03 до 1.20 , которые использованы для изготовления секций МТЭ. Разработаны метод, математические модели, а также программное обеспечение для моделирования МТЭ. В результате оптимизирована конструкция МТЭ и рассчитано значение его кпд. Без учета тепловых и электрических потерь оно составляет $21.5 \%$, что значительно выше кпд обычного термоэлемента.

Обоснована структура КС в конструкции МТЭ, состоящая из нескольких контактных слоев, обеспечивающих выполнение следующих функций: омического контакта, адгезионного, диффузионно-барьерного и коммутационного слоев. Обоснованы критерии выбора материалов контактных слоев КС. Установлены факторы, определяющие стабильность ДБС, и определены материалы для ДБС. Для нанесения контактных слоев использовано магнетронное ионно-плазменное распыление. Использованы эффективные способы подготовки поверхности образцов ТЭМ для формирования КС. В результате анализа термической стабильности КС с использованием метода оже-электронной спектроскопии подтверждена эффективность ДБС. Получены КС с высокой адгезионной прочностью (>14МПа) и низким контактным сопротивлением $\left(\sim 10^{-9} \mathrm{OM} \cdot \mathrm{M}^{2}\right)$. Для увеличения толщины коммутационного слоя $\mathrm{Ni}$ (17-24 мкм) использовано его химическое осаждение из борогидридного электролита. Коммутация секций и шин в структуре МТЭ осуществлялась несколькими способами. При низких температурах использовали пайку. Для коммутации секций в МТЭ, при повышенных температурах, использовали способы, реализуемые посредством образования сплава Ni-In, эвтектического сплава Ni-Sn, использования бондинга слоев $\mathrm{Au}-\mathrm{Au}$.

В результате исследования температурных зависимостей ТКЛР материалов установлено следующее. Основной проблемный участок в структуре МТЭ при контакте секций на основе $\mathrm{PbTe}$ и GeTe с секциями на основе SiGe. В области температур $900 \mathrm{~K}$ ТКЛР материалов этих секций различаются в 6 раз. Для устранения механических напряжений, возникающих при высоких температурах, предложено формировать в структуре КС демпфирующий слой из композиционного материала на основе углеродных нанотрубок.

Для оценки термической стабильности с помощью дифференциальной сканирующей калориметрии установлено, что ТЭМ термически стабильны в рекомендуемых интервалах рабочих температур. При использовании термогравиметрического анализа определено, что выше температуры $850 \mathrm{~K}$ для PbTe и GeTe начинается интенсивная сублимация. Экспериментально установлено, что защитные слои $\mathrm{Si}_{3} \mathrm{~N}_{4}$ и $\mathrm{SiO}_{2}$, полученные плазмохимическим осаждением, устраняют сублимацию ТЭМ до $1200 \mathrm{~K}$.

Таким образом, в данной работе определены пути и обоснованы способы повышения эффективности генераторных термоэлементов. Для реализации этих способов разработан комплекс мер, определяющих физикотехнологические основы создания многосекционных термоэлементов, позволяющих значительно увеличить кпд ТЭГ.

\section{Финансирование работы}

Работа выполнена при поддержке гранта Президента (проект № 075-15-2020-441).

\section{Конфликт интересов}

Автор заявляет, что у него нет конфликта интересов. 


\section{Список литературы}

[1] D. Zhao, G. Tan. Appl. Therm. Eng., 66, 15 (2014).

[2] M. Shtern, M. Rogachev, Y. Shtern, A. Kozlov, A. Sherchenkov, E. Korchagin. In: Proc. 2021 Int. Seminar on Electron Devices Design and Production (Prague, Czech Republic, 2021) p. 9444502.

[3] A. Martinez, S. Diaz de Garayo, P. Aranguren, M. Araiz. Energy Con-vers. Manag., 2351, 113992 (2021).

[4] Z. Soleimani, S. Zoras, B. Ceranic, S. Shahzad, Y. Cui. Energy Technol. Assess, 37, 100604 (2020).

[5] N. Jaziri, A. Boughamoura, J. Muller, B. Mezghani, F. Tounsi, M. Ismail. Energy Rep., 6, 264 (2020).

[6] Y. Ouyang, Z. Zhang, D. Li, J. Chen, G. Zhang. Annalen der Physik, 531 (4), 1800437 (2019).

[7] M. Shtern, M. Rogachev, Y. Shtern, A. Sherchenkov, A. Babich, E. Korchagin, D. Nikulin. J. Alloys Compd., 877, 160328 (2021).

[8] А.А. Шерченков, Ю.И. Штерн, Р.Е. Миронов, М.Ю. Штерн, М.С. Рогачев. Рос. нанотехнологии, 10 (11-12), 22 (2015).

[9] E. Symeou, Ch. Nicolaou, A. Delimitis, J. Androulakis, Th. Kyratsi, J. Giapintzakis. J. Solid State Chem., 270, 388 (2019).

[10] P. Dharmaiah, H.-S. Kim, C.-H. Lee, S.-J. Hong. J. Alloys Compd., 686, 1 (2016).

[11] W.H. Shin, K. Ahn, M. Jeong, J.S. Yoon, J.M. Song, S. Lee, W.S. Seo, Y.S. Lim. J. Alloys Compd., 718, 342 (2017).

[12] V. Ohorodniichuk, S. El-Oualid, A. Dauscher, C. Candolfi, P. Masschelein, S. Migot, P. Dalicieux, P. Baranek, B. Lenoir. J. Mater. Sci., 55, 1092 (2020).

[13] А.Т. Бурков, С.В. Новиков, Х. Танг, Я. Ян. ФТП, 51 (8), 1068 (2017).

[14] T. Zhu, Y. Liu, C. Fu, J.P. Heremans, J.G. Snyder, X. Zhao. Adv. Mater., 29, 1605884 (2017).

[15] А.А. Шерченков, Ю.И. Штерн, М.Ю. Штерн, М.С. Рогачев. Рос. нанотехнологии, 11 (7-8), 13 (2016).

[16] G. Tan, L.-D. Zhao, M.G. Kanatzidis. Chem. Rev., 116, 12123 (2016).

[17] M.Yu. Shtern, M.S. Rogachev, A.A. Sherchenkov, YuI. Shtern. Mater. Today: Proceedings, 84, 295 (2020).

[18] S. Twaha, J. Zhu, Y. Yan, B. Li. Renew. Sustain. Energy Rev., 65, 698 (2016).

[19] M.Yu. Shtern, I.S. Karavaev, Y.I. Shtern, A.O. Kozlov, M.S. Rogachev. Semiconductors, 53, 1848 (2019).

[20] C.L. Cramer, H. Wang, K. Ma. J. Electron. Mater., 47, 5122 (2018).

[21] P.H. Ngan, L. Han, D.V. Christensen. J. Electron. Mater., 47, 701 (2018).

[22] L. Cai, P. Li, Q. Luo, P. Zhai, Q. Zhang. J. Electron. Mater., 46, 1552 (2017).

[23] M. Shtern, M. Rogachev, Y. Shtern, D. Gromov, A. Kozlov, I. Karavaev. J. Alloys Compd., 852, 156889 (2021).

[24] S.-W. Chen, A.H. Chu, D.S.-H. Wong. J. Alloys Compd., 699, 448 (2017).

[25] H.-Y. Zhou, W.-Y. Zhao, G. Liu, H. Cheng, Q.-J. Zhang. J. Electron. Mater., 42, 1436 (2013).

[26] X.Y. Yang, J.H. Wu, M. Gub, X.G. Xia, L.D. Chen. Ceram. Int., 42, 8044 (2016).
[27] Д.Г. Громов, Ю.И. Штерн, М.С. Рогачев, А.С. Шулятьев, Е.П. Кириленко, М.Ю. Штерн, В.А. Федоров, М.С. Михайлова. Неорг. матер., 52 (11), 1206 (2016).

[28] J. de Boor, C. Gloanec, H. Kolb, R. Sottong, P. Ziolkowsk, E. Mul-ler. J. Alloys Compd., 632, 348 (2015).

[29] J. De Boor, D. Droste, C. Schneider, J. Janek, E. Mueller. J. Electron. Mater., 45, 5313 (2016).

[30] T. Sakamoto, Y. Taguchi, T. Kutsuwa, K. Ichimi, S. Kasatani, M. Inada. J. Electron. Mater., 45, 1321 (2016).

[31] S.H. Park, Y. Kim, C.Y. Yoo, G. Yoon. J. Vac. Sci. Technol. A, 34, 061101 (2016).

[32] Y. Sadia, T. Ohaion-Raz, O. Ben-Yehuda, M. Korngold, Y. Gelbstein. J. Solid State Chem., 241, 79 (2016).

[33] M.Yu. Shtern. In: Proc. 2019 IEEE Conf. of Russian Young Researchers in Electrical and Electronic Engineering (Moscow, Russia, 2019) p. 1920.

[34] Yu. Stern, L. Pavlova, R. Mironov. J. Electron. Mater., 39 (9), 1422 (2010).

[35] Z.-G. Chen, G. Han, L. Yang, L. Cheng, J. Zou. Progr. Nat. Sci., 22, 535 (2012).

[36] Технология толстых и тонких пленок, под ред. А. Рейсмана, К. Роуза (М.: Мир, 1972). [Пер. с англ.: Thick and thin films for electronic applications, ed. by A. Reisman, K. Rose (N.Y., Wiley, 1971)].

[37] S.M. Sze, K.K. Ng. Physics of Semiconductor Devices (N.Y., Wiley, 2007).

[38] E.H. Rhoderick, R.H. Williams. Metal-Semiconductor Contacts (Oxford, University Press, 1988).

[39] R. Yang, S. Chen, W. Fan, X. Gao, Y. Long, W. Wang, Z.A. Munir. J. Alloys Compd., 704, 545 (2017).

[40] С.И. Новикова. Тепловое расширение твердых тел (М., Наука, 1974).

[41] S. Yoneda, M. Kato, I.J. Ohsugi. J. Appl. Phys., 107, 074901 (2010).

[42] Y. Hikage, S. Masutani, T. Sato, S. Yoneda, Y. Ohno, Y. Isoda, Y. Imai, Y. Shinohara. In: Proc. 26th Int. Conf. on Thermoelectrics (Jeju, Korea, 2007) p. 331.

[43] H. Wiedemeir, P.A. Siemers. J. Inor. and General Chem., 431, 299 (1977).

[44] А.С. Охотин, А.А. Ефремов, В.С. Охотин, А.С. Пушкарский. Термоэлектрические генераторы (М., Атомиздат, 1971).

[45] V. Ravi, S. Firdosy, T. Caillat, E. Brandon, K. Van Der Walde, L. Maricic, A. Sayir. J. Electron. Mater., 38, 1433 (2009).

[46] J.P. Dismukes, L. Ekstrom, R.J. Paff. J. Phys. Chem., 68, 3021 (1964).

[47] В.М. Глазов, В.Б. Кольцов, В.З. Куцова, А.Р. Регель, Ю.Н. Таран, Г.Г. Тимошина, К.И. Узлов, Э.С. Фалькевич. ФТП, 25 (4), 588 (1991).

[48] Пат. № 2601243. Способ получения термоэлектрического элемента. Ю.И. Штерн, Д.Г. Громов, М.С. Рогачев, М.Ю. Штерн, С.В. Дубков. 
Multi-section thermoelements, advantages and problems of their creation

\section{M.Y. Shtern}

National Research University

of Electronic Technology,

124498 Moscow, Zelenograd, Russia

Abstract In this work, the ways of increasing the efficiency of thermoelectric generators are considered. These include an increase in the figure of merit of thermoelectric materials, as well as an increase in the temperature difference between hot and cold junctions of thermoelements and, accordingly, the range of their operating temperatures. The expediency of using thermoelements with multi-section legs has been substantiated. For their creation, effective thermoelectric materials with operating temperatures in the range of $300-1200 \mathrm{~K}$ have been proposed. A technique for modeling such thermoelements has been developed. Structures and materials of effective contact systems for multisection thermoelements have been proposed, a technology for their manufacture has been developed. Ways of switching sections in thermoelement legs are considered. The thermal expansion of thermoelectric materials is investigated and a method for damping thermal stresses in the design of a thermoelement is proposed. The problem of thermoelectric material sublimation at high temperatures was solved by using protective coatings. 